\title{
Genetic Analysis of Tropical Orchid Hybrids (Dendrobium) with Fluorescence Amplified Fragment-length Polymorphism (AFLP)
}

\author{
N. Xiang1 and Y. Hong ${ }^{2}$ \\ Temasek Life Sciences Laboratory, 1 Research Link, The National University of Singapore, \\ Singapore 117604 \\ L.T. Lam-Chan ${ }^{2}$ \\ Horticulture Branch, Agri-food and Veterinary Authority of Singapore, Sembawang Research Station, \\ Singapore 769194
}

AdDitional INDEX wORDs. tropical orchids, Dendrobium, AFLP, genetic profiling, DNA fingerprinting, plant breeder rights, UPOV

\begin{abstract}
Intensive breeding activities of tropical orchids have given rise to many hybrids, among which genetic relationships are difficult to evaluate due to free interbreeding of different species in the same genus or even from different genera, the use of hybrids for further breeding, use of abbreviated or trade names and sometimes intentional non-disclosure of parentage for commercial considerations. We have subjected 43 popular commercial Dendrobium hybrids to fluorescence amplified length polymorphism (AFLP) analysis and their genetic relationship was estimated. The hybrids bearing flowers of similar shapes and colors were clustered into five groups. Each hybrid tested had a distinct AFLP fingerprint profile except the tissue culture mutants. Sibling hybrids were closely clustered (with genetic distance $<0.09$ ) followed by those sharing one parent. These results suggest that AFLP fingerprint profiling gives accurate and objective estimation of genetic relationship of the Dendrobium hybrids tested. Our study also found that the AFLP fingerprint profiles were uniform in different parts of tested plants, stable among individuals in vegetatively propagated populations throughout different growth periods. We conclude that AFLP fingerprint profiling has the potential to be an integral part of current new plant varieties protection sytems.
\end{abstract}

Orchidaceace is one of the largest families of flowering plants in the world with 25,000 to 30,000 species and more than 150,000 artificial hybrids. One of the most unusual things one notices in the orchid family is that many different species can freely interbreed to form hybrids. Hybrids in turn can interbreed with other species or hybrids to form second, third, fourth, fifth, etc. generation hybrids. Moreover, orchids from different genera can also hybridize. Some artificial intergeneric hybrids involving up to six genera have been created by man, e.g., Brilliandeara $=$ Aspasia $\times$ Brassia $\times$ Cochlioda x Miltonia x Odontoglossum x Oncidium (Tan and Hew, 1995). Intensive breeding activities over many years have given rise to many commercial cut flower hybrids (with Dendrobium forming one of the largest groups) for their good combination of appreciable flower color and shape, vase life and yield. Each orchid breeding cycle typically takes 5 to 7 years with requirement of space and labor for selecting from thousands of progenies. Commercial orchid breeders generally choose parents for breeding based on favorable characteristics and experience. When hybrids are fertile and used for further breeding, the identities of progenies could become untraceable. The practices of using abbreviated or trade names and sometimes intentional non-disclosure of parentage (many commercial hybrids are not registered with Royal Horticultural Society) for commercial considerations further complicate genetic relationships among hybrids.

DNA markers reflect differences in the DNA sequences of chromosomes derived from different progenitors. They arise as

Received for publication 2 Oct. 2002. Accepted for publication 22 Apr. 2003 We would like to thank Lee Siew Mooi and Lim Chai Song from Agri-Food \& Veterinary Authority of Singapore for help in collection of orchid samples.

${ }^{1}$ Also affiliated with Institute of Animal and Plant Quarantine, AQSIQ, 100029, Beijing, China.

${ }^{2}$ To whom reprint requests should be addressed; e-mail hongy@tll.org.sg. a result of mutations as well as rearrangements in the DNA sequence intervening between two restriction sites, or two priming sites. Molecular marker techniques can help resolve relationships among plant materials, which would help breeders to maximize variation among progenies by going for combinations genetically farthest apart.

Amplified fragment length polymorphism (AFLP) is a technique developed by Vos et al. (1995) through which selected restriction fragments from the digestion of total plant DNA are amplified by the polymerase chain reaction (PCR). The resulting DNA fingerprint profile includes a large number of genetic markers. It has a higher multiplex ratio, defined as the number of information points analyzed per experiment, than other types of techniques, such as Restriction fragment length polymorphism (RFLP) and Random amplified polymorphic DNA (RAPD). It has proven to be an extremely effective tool for distinguishing closely related genotypes. This technique has been used to analyze genetic relationships in cacao(Perry et al., 1998), hop(Hartl and Seefelder, 1998), nectarine and peach (Manubens et al., 1999), apple (Zhu et al., 2000) cassava (Roa et al., 1997) and maize (Marsan et al., 1998) but there is no report on applying this technique to tropical orchids. RAPD analysis of genetic closeness of several Vanda species (Lim et al. 1999) supported the suggestion that terete-leaved Vanda teres and Vanda hookeriana be classified in the separate genus Papilionanthe and that Vanda sanderiana should remain in the genus Vanda.

Over the years, there has been the more intensive drive towards protection of new plant varieties. Many more countries are becoming members of International Union for the Protection of New Varieties of Plants (UPOV). According to UPOV requirements, a new plant variety should be distinct, uniform and stable (DUS). Being a robust technique with high level of resolution, AFLP fingerprint profiling can potentially provide objective and scientific support 
to administration of plant breeder rights. There is the need for a systematic comparative study of phenotype descriptions with AFLP fingerprint profiling on multiple commercial cultivars in accordance with the DUS criteria.

Singapore ranks second in the world for export of tropical orchid cut flowers with Dendrobium hybrids forming the largest export genus (Pathfast Publishing, 2002). One objective of this study was to evaluate the genetic relationship of popular commercial Dendrobium hybrids with AFLP analysis to help breeders choose parental plants for breeding. The second objective was to evaluate the feasibility of using AFLP fingerprint profiling for protection of new plant varieties. Fluorescence-labeled primers instead of radioactive labeled primers were used to allow more objective and more sensitive detection of fragments. Based on the DUS criteria of UPOV, we evaluated distinctiveness of AFLP fingerprint profiles for hybrids tested, uniformity of these profiles in different parts of one plant and stability of these profiles in vegetative propagated populations at different developmental stages.

\section{Materials and Methods}

Plant Material. Efforts were made to have a comprehensive and representative collection of commercial Dendrobium hybrids from seven orchid farms in Singapore (Table 1). Seven sibling hybrids of Sonia were collected from three farms. Two tissue culture mutants were also collected together with their mother plants. These Dendrobium hybrids bear flowers of different shapes and shades of white, pink, purple, red, blue, green and yellow colors. For those registered with Royal Horticultural Society (RHS), grex epithets and cultivar epithets were used. Trade names were adopted from breeders/growers for those unregistered hybrids. Clean leaves, inflorescences, flowers and aerial roots were cut from plants, wrapped in aluminum foil and kept in a cool icebox during field collection and stored at $4{ }^{\circ} \mathrm{C}$ until DNA isolation. Samples were collected randomly from those vegetative propagated populations of potted plants.

DNA isolation. Genomic DNAs were isolated from $2 \mathrm{~g}$ of materials by a modified CTAB method (Xie and Hong, 2001). Quality and quantity of DNA was checked by $1 \%$ agarose gel electrophoresis.

AFLP ANALYSIS. AFLP was performed according to the procedure of AFLP Plant Mapping Kit of Perkin-Elmer Corporation. First, genomic DNA $(\approx 0.5 \mu \mathrm{g})$ was digested with MseI and EcoRI and ligated with adapters overnight at room temperature. The product was amplified in the preselective amplification step using primers with one selective base in a total volume of 20 $\mu \mathrm{L}$. Selective amplification was conducted with three selective bases at the 3' end of both primers. The EcoRI primer was labeled with fluorescence dye FAM (blue) at the 5' end. After selective amplification, amplified fragments were separated on polyacryamide gel with an ABI Prism 377 DNA sequencer after mixing with DNA size standards labeled with fluorescent dye TAMRA (yellow). Data of fragments were processed with Genescan and Genotyper of Perkin Elmer for size and intensity of each band. Composite gel pictures were visually evaluated for quality. Each reaction was repeated at least twice. AFLP bands were scored as 0 (absent) and 1 (present) and only those clear and discrete bands were used for genetic similarity calculation. Similarity index (SI) was calculated according to simple matching method (Apostol et al., 1993) with formulation $\mathrm{SI}=(\mathrm{n} 11+\mathrm{n} 00) / \mathrm{n}$ where $\mathrm{n} 11$ is the number of bands shared between two samples and n00 the number of bands absent from both samples and $\mathrm{n}$ is the total number of bands. Genetic distance is defined as 1-SI. UPGMA (unweighted pair-group method using arithmetic averages) method was used for clustering and drawing dendrogram with the software package NTSYSpc (Exeter Software, New York).

\section{Results and Discussions}

The ChOICE OF SUITABle PRIMER COMbinations. Forty-seven primer combinations with three selective bases at 3' end were tested on seven Dendrobium hybrids (Anna, Pink, Tay Sweee Keng, Sonia, Ekapol, Renapa, and Caesar). The number of bands obtained per primer combination ranged from four to about 150 between 100 and 500 bp in size. A good primer combination should give a large number of well-separated polymorphic bands of similar signal intensity. A subjective evaluation method based on number, distribution and intensity uniformity of bands was used to judge each primer combination. The following 12 primer combinations were found suitable for Dendrobium hybrids with 50 to 100 evenly distributed bands between 100 and $500 \mathrm{bp}$ (EcoRI-ACT/MseI-CAA, EcoRI-ACT/MseI-CAC, EcoRI-ACA/ MseI-CAC, EcoRI-ACA/MseI-CAT, EcoRI-ACA/MseI-CTG, EcoRI-AAG/MseI-CTA, EcoRI-AGG/MseI-CAT, EcoRI-AGG/ MseI-CTT, EcoRI-ACG/MseI-CAT, EcoRI-ACG/MseI-CAA, EcoRI-ACG/MseI-CAC and EcoRI-ACG/MseI-CTG). Two primer combinations were chosen for analysis in this project: EcoRI-ACG /MseI-CAA and EcoRI-AGG/MseI-CAT.

GENETIC RELATIONSHIP AMONG THE 43 Dendrobium HYBRIDS. The two primer combinations (EcoRI- ACG/MseI-CAA and EcoRI AGG/MseI-CAT) generated 108 discrete amplified fragments between 75 and 500 bp for the 43 Dendrobium hybrids (56 fragments for EcoRI-ACG/MseI-CAA and 52 fragments for EcoRI AGG/MseI-CAT). Ninety bands were polymorphic (83\%).

Genetic distances among hybrids were calculated by using the simple similarity data matrix according to Apostol et al. (1993) (Fig. 1). We chose it from several data matrix formula because it took into account additional similarity between cultivars that lack bands at polymorphic positions. This counteracts the possible overestimation of diversity. It was also adapted to evaluate diversity among arabidopsis ecotypes (Erschadi et al., 2000).

The dendrogram shows that at genetic distance of 0.25 , the 43 cultivars are divided into five groups: group A with a single member of Aaron Law; group B with 20 members represented by Lucian Pink, all bearing white or pink flowers; group C with 15 members represented by Sonia, all bearing pink flowers; Group $\mathrm{D}$ with four members bearing green flowers; Group E with three members bearing yellow flowers. Groups A, B, and C will meet group D and $\mathrm{E}$ at genetic distance of 0.34 .

There were two pairs of hybrids not distinguishable from each other (with genetic distance 0\%): Lucian Pink with Lucian White; Ekapol with Erika. The conclusion held even after we used four other primer combinations to obtain 200 more discrete bands (data not shown). According to the breeders, Lucian white was actually a tissue culture mutant of Lucian Pink bearing white flowers instead of pink flowers. Similarly, Erika was the tissue culture mutant bearing pink flower instead of purple flower of Ekapol. It is possible that the number of AFLP primer combinations was not enough to detect mutations. Since the two tissue culture mutants were similar in all other features to their mother plants except with less anthocyanin synthesis (lighter colored or white flowers) in flowers and it was well studied that transcription of anthocyanin regulatory genes in maize could be down regulated by heritable paramutation (see Chandler et al., 1996 for a review), we suggest 
Table 1. Parentage for Dendrobium hybrids according to RHS orchid registry and features of flowers.

\begin{tabular}{|c|c|c|c|}
\hline Hybrids & Seed parent & Pollen parent & Features of flower \\
\hline Aaron Law (a) ${ }^{Z}$ & Lucky Belle & Ng Eng Cheow & Sepals are soft purple in color; lateral petals are purple and broad at the upper enc \\
\hline White Angel (b) & Caesar & Neo-Hawaii & $\begin{array}{l}\text { Sepals and petals are white, thin and elongated. Column is tinged with yellow; } \\
\text { lip is white }\end{array}$ \\
\hline Angel (c) & $\mathrm{NR}^{\mathrm{y}}$ & NR & Similar to White Angel \\
\hline White Fairy (c) & Singapore White & Walter Oumae & Sepals and petals are white and round \\
\hline \multicolumn{4}{|c|}{ Column is light yellow and lip is white } \\
\hline Fairy White (d) & NR & NR & Shape and color similar to Fairy White \\
\hline Shavin White (e) & Walter Oumae & Queen Florist & $\begin{array}{l}\text { Sepals and lateral petals are white with very fine light green veins. } \\
\text { Lip is pure white }\end{array}$ \\
\hline \multicolumn{4}{|c|}{ Column is greenish yellow } \\
\hline Lucian Pink (c) & Walter Oumae & Lois Anderson & Sepals and petals are pastel pink and whitish at the base. Lip is light pink. \\
\hline Lucian White (c) & $\mathrm{NA}^{\mathrm{x}}$ & NA & $\begin{array}{l}\text { Sepals and petals are white. Shape similar to Lucian Pink. Tissue culture mutant } \\
\text { of Lucian Pink }\end{array}$ \\
\hline California Pink (c) & NR & NR & Sepals and petals are lighter pink in color than Lucian Pink \\
\hline Apple Pink (a) & NR & NR & $\begin{array}{l}\text { Sepals and petals are pink with white margins and are rounder than those of } \\
\text { Lucian Pink }\end{array}$ \\
\hline Akiko Pink (b) & Singapore White & Ekapol & Sepals and petals are pink in color, round and intermediate in shape \\
\hline Tuang Pink (a) & Walter Oumae & Kamala & $\begin{array}{l}\text { White sepals; light pink at the upper half of lateral petals. Sepals and petals } \\
\text { are thin, elongated and a little curled }\end{array}$ \\
\hline Burgundy (c) & NR & NR & Sepals and petals are purple red, thin and elongated in shape \\
\hline Masako Deguchi (b) & Multico White & Sonia & $\begin{array}{l}\text { Sepals are white and petals are pink with white base. Column is light yellow } \\
\text { and lip is pink. }\end{array}$ \\
\hline Blue (c) & NR & NR & Sepals and petals are bluish purple in color \\
\hline Genting Blue (d) & Ng Eng Cheow & Kultana & Sepals and petals are bluish purple in color \\
\hline Chanel (c) & Majestic & D. lasianthera & $\begin{array}{l}\text { Sepals and petals are white with puplish-pink veins; shape of sepals and petals } \\
\text { are thin, elongated and curled }\end{array}$ \\
\hline Mother Teresa (c) & White Fairy & Candy Stripe & Sepals and petals are white in color with prominent purple stripes \\
\hline Pramot $(\mathrm{c})$ & Toshiko & Lois Anderson & Sepals and petals are light pink in color \\
\hline Sakura (c) & Otome & Snowflake & Sepals and petals are light pink; shape of petals are rounder than Pramot \\
\hline Hiang Beauty (c) & Jaq-Hawaii & Pale Face & $\begin{array}{l}\text { Sepals are white in color and petals are white with purple veins } \\
\text { Column is purple-red and lip is white with purple veins }\end{array}$ \\
\hline Anna (c) & NR & NR & $\begin{array}{l}\text { Sepals are light pink with white edges at the lower half; petals are darker pink } \\
\text { Shape of lateral petals round, Lip is dark pink }\end{array}$ \\
\hline Cherry Pink (c) & NR & NR & Sepals and petals are purple-red in color; petals round in shape \\
\hline Cleopatra Beauty (b) & Tora Ohashi & Diamond Queen & $\begin{array}{l}\text { Sepals and petals are purple red in color with white tips at the lateral petals } \\
\text { Lip deep purple }\end{array}$ \\
\hline Caesar (f) & D. phalaenopsis & D. stratiotes & Sepals light pink with white margins, lateral petals are pink, \\
\hline Sonia (b) & Caesar & Tomie Drake & $\begin{array}{l}\text { Sepals have white background and are reddish purple at upper half; pointed } \\
\text { ends. Lateral petals are purple in color with a little white at the base and shape } \\
\text { is broad }\end{array}$ \\
\hline Eu Sua Kui (a) & NA & NA & Similar to Sonia \\
\hline Sonia 'Joe' (b) & NA & NA & Similar to Sonia except that the lip is bigger; sibling of Sonia \\
\hline Sonia 2 (b) & NA & NA & Similar to Sonia except that the sepals are lighter in color; sibling of Sonia \\
\hline Sonia 'Bond' (c) & NA & NA & Similar to Sonia, sibling of Sonia \\
\hline Bond 17 (a) & NA & NA & Similar to Sonia, sibling of Sonia \\
\hline Ekapol 'Red' (c) & Lim Hepa & Tomie Drake & $\begin{array}{l}\text { Sepals are dark purplish-red with thin white margins and tips; petals are dark } \\
\text { purplish red. Column is yellow and lip is dark puplish red }\end{array}$ \\
\hline Erika (c) & NA & NA & $\begin{array}{l}\text { Sepals and petals are of an even light pastel pink color. Tissue culture mutant } \\
\text { of Ekapol }\end{array}$ \\
\hline Pink (f) & NR & NR & Sepals are pink with white tips; lateral petals and lip are dark pink \\
\hline Renapa (f) & NR & NR & Sepals are pinkish with white tips; lateral petals. Lip is pink \\
\hline \multicolumn{4}{|c|}{ Possibly it is D. Lim Hepa $\mathrm{x}$} \\
\hline Tay Swee Keng (c) & Jaquelyn Concert & Irene Cheong & Sepals, lateral petals and lip are all dark purple \\
\hline Burana Jade (e) & Bangkok Green & Burana Fancy & Sepals and petals are yellow-green, lip is green with tinge of purple \\
\hline Jade (c) & Marie Beebe & Aina Haina & Sepals and petals are yellow-green; lip is green \\
\hline Green (c) & $\mathrm{NR}$ & NR & $\begin{array}{l}\text { Sepals and petals and the lip are yellowish green with darker veins. Columns } \\
\text { are green }\end{array}$ \\
\hline Yong Kok Wah (c) & Mary Trowse & D. schulleri & $\begin{array}{l}\text { Petals and lateral sepals are greenish yellow with darker veins. Column and } \\
\text { lip are greenish yellow with light purple veins }\end{array}$ \\
\hline Sharifah Fatimah (c) & Lim Chong Min & D. May Neal & $\begin{array}{l}\text { Sepals and petals are a light mustard yellow with darker veins; } \\
\text { lip yellow with light purple veins }\end{array}$ \\
\hline Sharifah Fatimah-2 (c) & NA & NA & $\begin{array}{l}\text { Similar to Sharifah Fatimah, slightly lighter in color. Sibling of Sharifah } \\
\text { Fatimah }\end{array}$ \\
\hline Sri-Siam (c) & Siam & May Neal & Sepals and petals are evenly yellow and thin and elongated. Lip is reddish purple \\
\hline
\end{tabular}

zSources of Dendrobium hybrids: (a) Kimtek Nursery, (b) Orchid Station, (c) Toh Garden, (d) Kim Seng Nursery, (e) Blue Mountain Nursery, (f) Orchidville. yNR = not registered with RHS.

${ }^{\mathrm{N} A}=$ not applicable.

the possibility that the tissue culture process had introduced similar epigenetic modifications to genes involved in anthocyanin synthesis. Such modifications could not be detected with our AFLP procedure since there was nochange ofDNAsequence. This possibility, however, needs to be further investigated.

We have included seven sibling hybrids in our experiment to evaluate their genetic relationship. Not surprisingly, the seven Sonia hybrids from three nurseries were closely clustered with genetic 


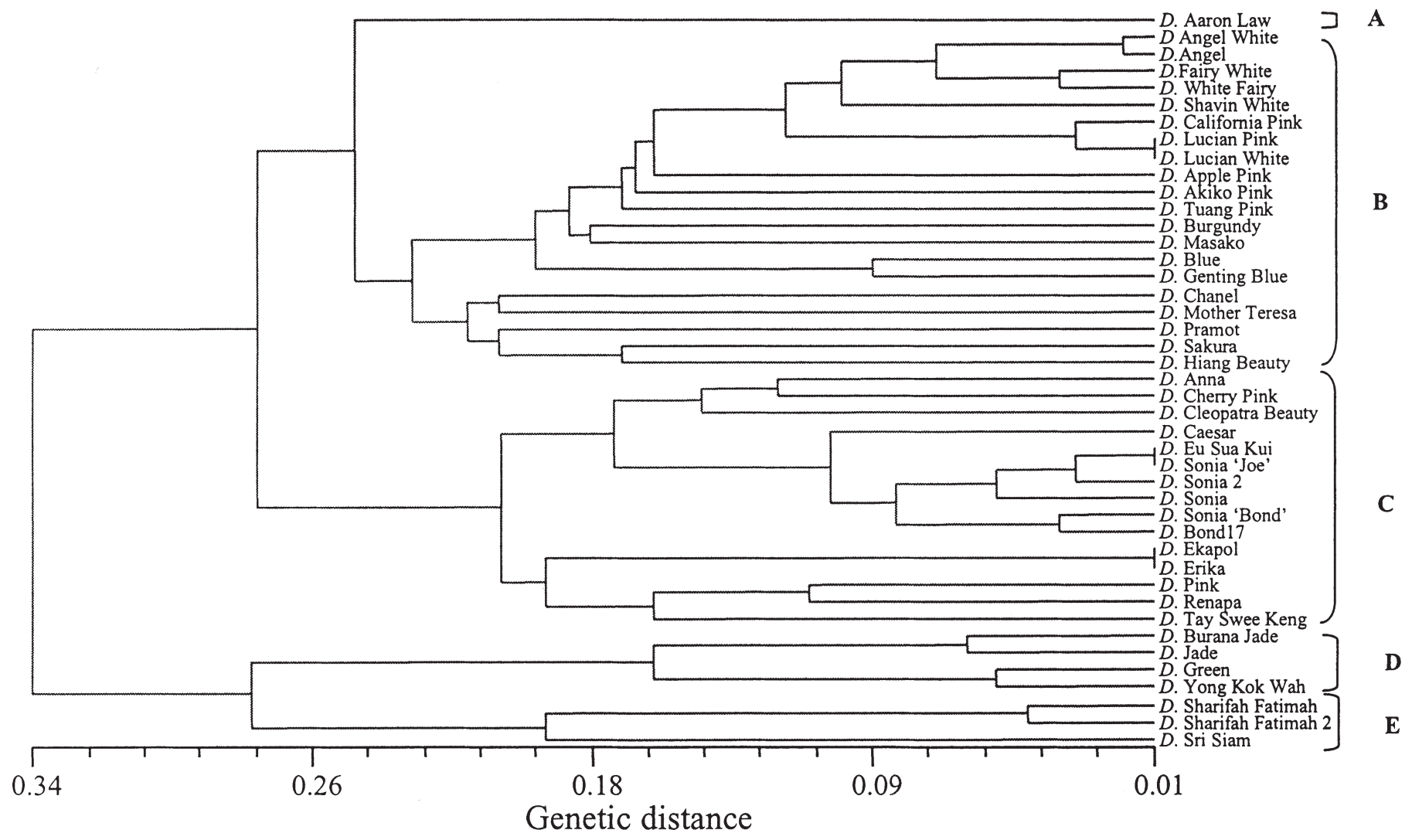

Fig. 1. Dendrogram of the Dendrobium hybrids

distance less than 0.09 among them. Their flowers were similar in shape, different only in shades of the pink color and sizes (see Table 1 for details). Eu Sua Kui and Sonia Joe were from two nurseries, genetically homogenous and morphologically in-distinguishable. It is possible that they were the closest related siblings. They could also have been propagated from the same mother plant but named differently by different farms for commercial reasons.

Considering that the seed parent of Sonia (Ceasar) was clustered with Sonia sibling hybrids at genetic distance 0.1, we suggest to use genetic distance of 0.09 to define sibling plants. This definition agrees well with the pair of Sharifah Fatimah and Sharifah Fatimah-2 that were known to us as siblings. This definition would pair Angel with Angel White, Fairy White with White Fairy, California Pink with Lucian Pink, Genting Blue with Blue, Burana Jade with B. Jade, Green with Yong Kok Wah as siblings despite the lack of parentage record in RHS for one in a pair. Morphologically, flowers of these suspected siblings were very similar. Feedback from farmers also confirmed such pairing. The only exception is the pair of White Angel with White Fairy with genetic distance of 0.082 . They share neither seed nor pollen parents according to RHS orchid registry. Further trace of the family trees for these two hybrids revealed the high level of percentage contribution of antecedent orchid D. phalaenopsis $(50 \%, 42 \%)$ and D. grantii $(25 \%$, $37.5 \%$ ) (RHS Information System 2002). This illustrates that AFLP fingerprint profiling can reveal genetic relationship that might not be obvious from parentage record. Morphologically, flowers for these two hybrids are all white, with White Fairy having slightly broader sepals and pedals. We conclude that, in general, genetic distance of 0.09 could be used to define siblings.

About $50 \%$ of the hybrids tested were registered with Royal Horticulture Society (RHS Information System 2002, parentage of registered orchids can be checked athttp://www.rhs.org.uk/research/ registerpages/orchidsearch.asp). We found the RHS parentage record consistent with genetic relationship derived from our AFLPanalysis. Caesar was the seed parent of Sonia and clustered closely to cultivars of Sonia (at genetic distance 0.1). White flower hybrid Shavin White was clustered close to White Fairy (at genetic distance 0.1 ) and both had Walter Oumae as one parent. Yellow flowering Sharifah Fatimah and Sri-Siam (at genetic distance of 0.19) all had May Neal as the pollen parent.

Table 2. Evaluation of the uniformity of AFLP fingerprint profiles in different organs and their stability in vegetative propagated Dendrobium populations and at different developmental stages.

\begin{tabular}{lll}
\hline Hybrids & Samples & AFLP fingerprint profiles \\
\hline Aaron Law & Leaf, inflorescence, flower and aerial root from one mother plant & Uniform \\
& 25 random samples from a population of 10,000 plantlets (6 months after potting) & Same profile as mother plant \\
Akiko Pink & 9 random samples from a population of 1,200 plantlets (12 months after potting) & Same profile as mother plant \\
& Leaf, inflorescence, flower and aerial root from one mother plant & Uniform \\
& 26 random samples from a population of 2,400 plantlets (6 months after potting) & 24 with the same profile as mother plant; two variants \\
& 20 random samples from a population of 4,000 plantlets (12 months after potting) & Same profile as mother plant \\
Lucian Pink & 19 random samples from a population of 5,000 plantlets (18 months after potting) & Same profile as mother plant \\
& Leaf, inflorescence, flower and aerial root from one mother plant & Uniform \\
& 20 random samples from a population of 5,000 plantlets (4 months after potting) & Same profile as mother plant \\
& 21 random samples from a population of 5,000 (3.5-4 year old after potting, flowering) & Same profile as mother plant \\
\hline
\end{tabular}


CONSISTENCY OF AFLP FINGERPRINT PROFILES IN DIFFERENT ORGANS OF PLANTS, IN VEGETATIVE PROPAGATED POPULATION AND AT DIFFERENT DEVELOPMENTAL STAGES. Organs of orchids including leaf, inflorescence, flower and aerial root were collected from one mother plant of Lucian Pink, one mother plant of Akiko Pink and one mother plant of Aaron Law. Random leaf samples were also taken from vegetative propagated populations at different developmental stages (details see Table 2).

It was found from our study that AFLP fingerprint profiles were uniform in different organs, a different result from what was reported by Donini et al. (1997) that template DNAs extracted from different plant organs gave different AFLP patterns. We also found that the AFLP fingerprint profiles of these mother plants had been faithfully inherited by propagated seedlings at different developmental stages. There were only two variants for one Akiko pink population and the owner suggested that they might be from mixed up pots with another hybrid.

The use of restriction enzyme combination EcoRI-MseI and three selective bases for selective amplification was found suitable for distinguishing Dendrobium orchid hybrids tested. With the two primer combinations used, all hybrids except the tissue culture mutants had at least two AFLP markers different from others. The same primer combinations were also tested on other cultivars from genera Vanda, Aranda, Mokara and Oncidium. They gave good band patterns different from those for Dendrobium (data not shown), suggesting that they might be useful to orchids of other genera.

In recent years, the situation regarding the lack of legislation for protection of new plant varieties is changing mainly due to the requirement of World Trade Organization (WTO) agreement on Trade-related Aspect of Intellectual Property Rights (TRIPS). TRIPS requires WTO member states to provide protection for new plant varieties by patent and/or a separate system. Instead of setting up new systems, most member states choose to adopt Act of International Union for the Protection of New Varieties of Plants (UPOV) to provide protection for new plant varieties. According to UPOV requirements, new plant varieties must be novel, distinct, uniform and stable (DUS) to get Plant Breeder Rights. In our experiment, we found the AFLP technique useful in getting unique molecular identities for the tested Dendrobium orchid hybrids; their AFLP fingerprint profiles were uniform in different parts of a plant and stable among vegetative propagated seedlings at different developmental stages. The genetic difference detected is consistent with available information from breeders, morphological comparisons of flowers and parentage records of Royal Horticultural Society. Therefore we conclude that the AFLP technique is suitable to assist protecting new plant varieties. Breeders can make use of AFLP fingerprint profiling to prove distinctiveness, uniformity and stability of a potential new variety together with other morphological data. By matching the DNA fingerprint profile of a potential new variety with those of varieties already in a database (Hong and Chuah, 2003), administrators can narrow down choices for field comparison, thus saving time and cost. Differences in AFLP fingerprint profiles can serve as an objective support and scientific evidence for granting plant breeder rights. In addition, AFLP fingerprint profiling will be very useful in resolv- ing legal disputes on ownership of plant varieties especially when the AFLP profile of the cultivar in dispute has been deposited in a database. There are, however, several issues to be resolved before integrating AFLP into a plant variety protection system. One issue is the definition of novelty based on genetic analysis and reconciliation with morphological data. Our finding that AFLP failed to differentiate tissue culture mutants exemplifies one situation with discrepancy of morphological comparision with genetic analysis. Examples of other issues are the harmonization of technical details, cross-examination and accreditation of service providers.

\section{Literature Cited}

Apostol, B.L., W.C Black, P. Reiter, and B.R. Miller. 1993. Estimation of the number of full sibling families at an ovipositino site using RAPDPCR markers: Applications to the mosquito Aedes aegypti. Theor. Appl. Genet. 6:991-1000.

Chandler, V.L., W.B. Eggleston, and J.E. Dorweiler. 2000. Paramutation in maize. Plant Mol. Biol. 43:121-45.

Donini, P., M.L. Elias, S.M. Bougourd, and R.M.D. Koebner. 1997. AFLP fingerprinting reveals pattern differences between template DNA extracted from different plant organs. Genome 40:521-526.

Erschadi, G., G. Haberer, M. Schoniger, and R.A. Torres-Ruiz. 2000. Estimating genetic diversity of Arabidopsis thaliana ecotypes with amplified fragment length polymorphism (AFLP). Theor. Appl. Genet. 100:633-640.

Hartl, L. and S. Seefelder. 1998. Diversity of selected hop cultivars detected by fluorescent AFLPs. Theor. Appl. Genet. 96:112-116.

Hong, Y. and A. Chuah. 2003. A format for databasing and comparison of AFLP fingerprint profile. BMC Bioinformatics 4: 7.

Lim, S.H., P.C.P. Teng, Y.H. Lee, and C.J. Goh. 1999. RAPD Analysis of some species in the Genus Vanda (Orchidaceae). Ann. Bot. 83:193-196.

Manubens, A., S. Lobos, Y. Jadue, M. Toro, R. Messina, M. Lladser, and D. Seelenfreund. 1999. DNA isolation and AFLP fingerprinting of Nectarine and Peach varieties (Prunus persica). Plant Mol. Biol. Rpt. 17: 255-267.

Marsan,P.A.,P.Castiglioni,F.Fusari,M.Kuiper, and M.Motto. 1998. Genetic diversity and its relationship to hybrid performance in maize as revealed by RFLP and AFLP markers. Theor. Appl. Genet. 96:219-227.

The Orchid Database Company. 2002. The RHS orchid information system. Orchid Database Co., U.K.

Pathfast Publishing. 2002. International floriculture trade statistics 2002. Pathfast Publ., U.K.

Perry, M., M. Davey, B. Power, K. Lowe, F. Bligh, P. Roach, and C. Jones. 1998. DNAisolation and AFLPgenetic fingerprinting of Theobroma cacao (L.) Plant Mol. Biol. Rpt. 16: 49-59.

Roa, A.C., M.M. Maya, M.C. Duque, J. Tohme, A.C. Allem, and M.W. Bonierbale. 1997. AFLP analysis of relationships among Cassava and Manihot species. Theor Appl. Genet. 95:741-750.

Tan, H.T.W. and C.S. Hew. 1995. A guide of orchids of Singapore. $2^{\text {nd }}$ ed. Singapore Science Center, Singapore.

Vos, P., R. Hogers, M. Bleeker, M. Reijans, T. van de Lee, M. Hornes, A. Frijters, J. Pot, J. Peleman, M. Kuiper, and M. Zabeau. 1995. AFLP: a new technique for DNA fingerprinting. Nucl. Acids. Res. 23:4407-14.

Xie,D.Y.and Y.Hong. 2001. Agrobacterium-mediated genetictransformation of Acacia mangium. Plant Cell Rpt. 20:917-922.

Zhu, J., T. Wang, Y.J. Zhao, W. Zhang, and G.C. Li. 2000. Identification of apple varieties with AFLP molecular markers. Acta Hort. Sinica 27: 102-106. 